\title{
Overview of Six Months Activities in a New Unit of Management of Head Trauma in West Africa
}

\author{
Ouiminga Habib Abdoul Karim ${ }^{1, ~ *, ~ A l i h o n o u ~ T h i e r r y ~}{ }^{2}$, Zoungrana Noelie $^{3}$, Ndzana Diane ${ }^{4}$, \\ Ouedraogo Anatole Jean Innocent ${ }^{1}$, Compaore Linda Christelle ${ }^{4}$, Tamboura Habibata ${ }^{4}$ \\ ${ }^{1}$ Department of Orthopedics Traumatology and Neurosurgery, Tengandogo Teaching Hospital, Ouagadougou, Burkina Faso \\ ${ }^{2}$ Department of Traumatology Orthopedics and Restorative Surgery, HKM National Teaching Hospital, Cotonou, Benin \\ ${ }^{3}$ Department of Statistics and Epidemiology, Tengandogo Teaching Hospital, Ouagadougou, Burkina Faso \\ ${ }^{4}$ Department of Multipurpose Emergency, Tengandogo Teaching Hospital, Ouagadougou, Burkina Faso
}

\section{Email address:}

ouimkar@gmail.com (O. H. A. Karim), alihonou thierry@yahoo.fr (A. Thierry), wnoelie@yahoo.fr (Z. Noelie), diane.ndzana@yahoo.fr (N. Diane), anatoleji@yahoo.fr (O. A. J. Innocent), lyndacompaore777@gmail.com (C. L. Christelle), tambourahabibata@yahoo.fr (T. Habibata)

${ }^{*}$ Corresponding author

\section{To cite this article:}

Ouiminga Habib Abdoul Karim, Alihonou Thierry, Zoungrana Noelie, Ndzana Diane, Ouedraogo Anatole Jean Innocent, Compaore Linda Christelle, Tamboura Habibata. Overview of Six Months Activities in a New Unit of Management of Head Trauma in West Africa. International Journal of Neurosurgery. Vol. 4, No. 1, 2020, pp. 14-17. doi: 10.11648/j.ijn.20200401.14

Received: May 8, 2020; Accepted: May 27, 2020; Published: June 9, 2020

\begin{abstract}
Background: The aim of this study was to describe and compare with the literature data, the epidemiological and evolutionary aspects of the management of traumatic brain injury after six months of activities in a new hospital. Methods: This was a retrospective study that was performed at the neurosurgery unit of the Tengandogo Teaching Hospital. The analysis covered all admitted head trauma patients from May 1, 2014 to October 31, 2014. The variables studied were: frequency, age, sex, circumstances, mechanism, Glasgow score (GCS), care and evolution. Results: Over six months, 302 traumatized head injuries were recorded. The average age was 34.8 years old. The sex ratio was 3.79 ( $239 \mathrm{M} / 63 \mathrm{~W})$. Road traffic accidents accounted for $85.43 \%(\mathrm{n}=258)$ of etiologies, $80 \%$ of which were due to two-wheeled machines, followed by falls from a high place with $7.61 \%(n=23)$. In $5 \%(n=15)$ of cases, it was assault. Severe forms (GCS 3-8) accounted for $33.7 \%(n=102)$ of which $65.7 \%$ were associated with polytrauma. Moderate forms (GCS: $9-12)$ accounted for $21 \%(n=63)$ of the cases, $45.3 \%(\mathrm{n}=137)$ were benign forms (GCS: 13-15). Patients were medically treated in $73.5 \%(\mathrm{n}=119)$ of the cases, and $21 \%(n=63)$ were operated upon. Twenty-one patients $(6.6 \%)$ refused medical care. The mortality rate in severe forms was 38\%. Conclusion: Despite advances in resuscitation, overall mortality remains heavy. Sequelae are frequent, leading to difficulties in socio-professional and family reintegration in our low-income country. Prevention of these traumas plays a vital role.
\end{abstract}

Keywords: Epidemiology, Head Trauma, Prognosis

\section{Introduction}

Head injury is a common pathology, with considerable consequences in terms of morbi-mortality. It is the leading cause of death and disability in adults before the age of $35[1$, 2]. In Burkina Faso, this pathology becomes a concern because of the inflated number of traumatic brain injuries in relation with the increasing urbanization and the increase of the automobile fleet. The purpose of our study was to determine the frequency of head trauma and its evolution after management at the Tengandogo Teaching Hospital in six months of practice.

\section{Materials and Methods}

Type of study: This is a retrospective and descriptive study 
on all head trauma patients admitted to the department of Orthopedics Traumatology and Neurosurgery from May 1 to October 31, 2014.

Study Framework: The Tengandogo teaching hospital is located in Tengandogo, a peripheral district south of the city of Ouagadougou (Burkina Faso). This urban hospital with a capacity of 600 beds has been functional since 2010. It has an imaging center (CT, MRI, and Radiology), a multipurpose resuscitation unit of 30 beds, a functional rehabilitation center, an emergency services. The neurosurgery unit attached to the orthopedic traumatology service was created on December 15, 2013. It has a hospitalization capacity of 34 beds.

Study population: The follow-up of patients in the neurosurgery unit was clinical, and CT scans-on-evolution. It was done at 1 month, 3 months, 6 months, 12 and at the last decline at 18 months. A CT scan was performed at the last setback. The average decline was 9.5 months

Study variables: The variables studied were age, sex, circumstances, mechanism, prognosis and Glasgow score (GCS). This entity was divided into three groups of definition and specific management: severe head trauma (GCS 3-8), moderate head injury (GCS 9-12) and mild head injury (GCS 13-15).

Statistical analysis: The data was analyzed using the Epi Info 7 software. The analysis of the quantitative variables was done by estimating the average. The analysis of the qualitative variables was done using proportions.

\section{Results}

During this period, 1227 patients were admitted for surgical emergencies. Among these patients, 302 (24,61\%) head trauma patients were registered. The average age was 34.8 years with extremes of 4 years to 75 . There were 239 men for 63 women with a ratio of 3.79. Road traffic accidents accounted for the majority of cases with $85.43 \%$ $(n=258)$ of which $80 \%$ were caused by motorcyclists (Table 1). The frequency of trauma was higher in the months of May and June and in the early and late afternoon (Figures 1 and 2). Serious and moderate forms accounted for $54.7 \%$ $(n=165)$ of cases (Table 2). In these forms, the patients have all benefited from a cerebral CT scan. Intracranial lesions were present at imaging in $81.22 \%(n=134)$ of cases. The anatomical lesions observed are summarized in Table 3. Polytrauma existed in $65.7 \%(n=67)$ of the severe forms. Among the patients, $73.5 \%(\mathrm{n}=119)$ were medically treated, $21 \%(n=60)$ were operated, $6.6 \%(n=21)$ refused care, and 102 patients were admitted to resuscitation unit. The overall mortality rate is estimated at $15.23 \%(n=46)$ of which $38 \%$ in severe forms. The overall trend was favorable for the majority of cases (Table 2). In mild forms $45.3 \%(n=113)$ of patients returned to work in 72 hours, $18.5 \%(n=51)$ after 45 days and 3.3\% $(n=10)$ after 60 days in moderate forms. For the severe forms, $33 \%(n=30)$ resumed their activity after 6 months of functional rehabilitation and $34 \%$ had irreversible sequelae after 18 months.
Table 1. Distribution of patients according to etiologies of head trauma.

\begin{tabular}{lll}
\hline Circumstances & Number & Percentage (\%) \\
\hline Road Accidents & 258 & 85.43 \\
Fall from a high place & 23 & 7.61 \\
Assault & 15 & 5 \\
Sport Accident & 4 & 1.32 \\
Domestic accident & 2 & 0.66 \\
Total & 302 & 100 \\
\hline
\end{tabular}

Number

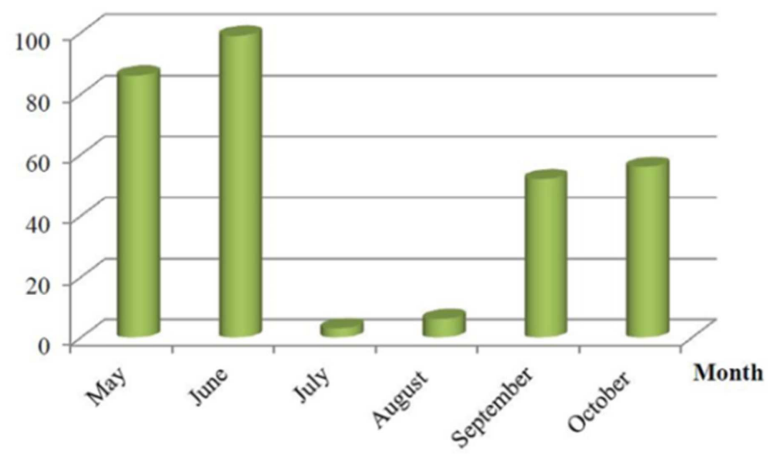

Figure 1. Distribution of traumatized head patients.

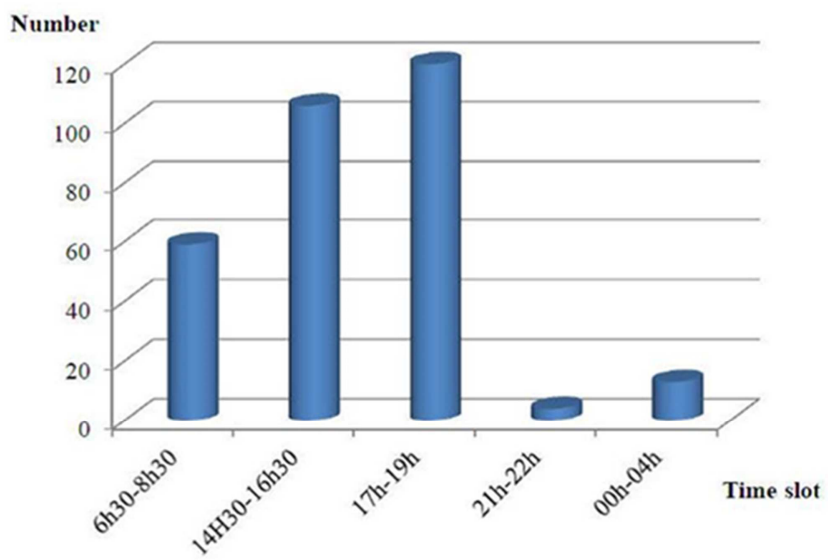

(a)

(b)

(c)

Figure 2. Distribution of head injuries according to hourly frequency peaks.

Table 2. Distribution of patients by severity of head trauma and evolution.

\begin{tabular}{llll}
\hline Clinical Forms & Number & Mortality & Favorable \\
\hline Severe forms & $33.7 \%$ & $38 \%$ & $89 \%$ \\
Moderate forms & $21 \%$ & $11 \%$ & $64 \%$ \\
Benign forms & $45.3 \%$ & 0 & $100 \%$ \\
Total & 100 & & \\
\hline
\end{tabular}

Table 3. Intracranial lesions.

\begin{tabular}{lll}
\hline Traumatic Lesions & Number & Percentage (\%) \\
\hline Subarachnoid haemorrhage & 60 & 44,77 \\
Hemorrhagic contusion & 25 & 18,65 \\
Cranio-cerebral wounds & 17 & 12,68 \\
Extra-dural hematoma & 14 & 10,44 \\
Scalp wound & 8 & 5,97 \\
Acute subdural Hematoma & 6 & 4.47 \\
Chronic dural hematoma & 4 & 2,98 \\
Total & 134 & 100 \\
\hline
\end{tabular}




\section{Discussion}

This study was conducted to obtain a statistical estimate of head trauma and its evolution after treatment at the Tengandogo teaching hospital in six months of practice. Worldwide, the incidence of head trauma exceeds 10 million people per year [1-4]. In Africa, they also affect low-income countries. They are reported to be the most common cause of neurosurgery admissions [2,5]. They represent $87 \%$ of neurosurgery admissions [2] and particularly affect a young and active population, mostly male. The population aged 30 to 40 is the most concerned $[1,2]$. More than $80 \%$ are in this age group, which is the most active in the population and the most vulnerable. In our context, the vast majority involved are students. The clear male predominance is also observed in other studies $[2,5]$. It would be due to the overrepresentation of men in road accidents and sports activities. Road traffic accidents remain the main cause in almost all countries $[2,4$, 5]. In our regions, the majority ( $85 \%)$ of accidents were caused by motorcyclists. The use of these machines would increase the risk of trauma $[2,5,6]$. It is the most common mechanism observed at the origin of these lesions [2]. These motorcyclists are numerous and ride on narrow and crowded roads sometimes without bike paths. It is the most accessible means of transport and is widely used in our developing countries. The purchase and driving of these machines is not subject to any regulation including obtaining a driver's license. Ignorance and non-compliance with traffic rules help to increase this rate. Fall injuries come in second place and are described in the literature with a rate of 33\% [7]. Most of these are tree falls that occur during the harvest season [7] of fruits (Mango, Shea, etc.). For a small number, it is a fall of scaffolding of workers, ignorance of the rules of safety is the main cause. These work accidents are responsible for severe polytrauma. The frequency of head trauma also appears to be related to periods of school and university activity. More than $90 \%$ of cases are distributed between the months of May and June. These months correspond to the end of the academic year for pupils and students and the last two months to the resumption of school and university activities, especially for the start of the school year and second-term exams. The majority of accidents occur early in the afternoon and early evening. These two time slots deserve special attention. These are hours of heavy road traffic. Workers and students use the same time slot to go to or leave from work. Moderate and severe forms of head trauma account for more than half of admissions, of which $33.7 \%$ are severe. They are expressing the severity of these traumas. Compared to other studies, it varies from 15 to $38 \%$ [2, 8-10]. Non-compliance with helmet use and speeding may partly explain the severity of these injuries. The existence of associated polytrauma is also one of the main causes $[4,11,12]$. Realization of a cerebral computed tomography was reserved only for moderate to severe forms as described by the authors $[7,8,13]$. It was sufficient and efficient for the inventory of anatomical lesions. His great interest was in therapeutic decision-making and surgical indication.
Trepanations, craniotomy by bone flap were the predominant gestures of the surgical management in our practice conditions as described by the authors [3, 8, 9, 14]. Lesions were essentially extra and subdural hematomas, depressed skull fracture. The reduced number of neurosurgeons means that many patients are not managed in due time. The overall mortality rate of head injuries was $9-21 \%$, and $47-50 \%$ in the severe trauma group $[2,5,8,13]$. In our exercise conditions, it lies in these intervals, of which $38 \%$ in severe forms. This is comparable to other studies in the literature $[3,5,7,13]$. Chesnut in 6 months of practice publishes a similar mortality rate in severe head trauma [9]. However, compared to the better equipped and organized hospital structures of developed countries that have a reduced rate and estimated at $30 \%$, the rates are underestimated. [3, 5, 9]. Patients with severe head trauma cannot reach our hospital in time for better management due to insufficient medical transport and qualified teams for first aid on the accident scene $[3,9]$. The mortality rate after 6 months of practice in our conditions was probably higher. Patients who died in the emergency department or upon arrival were not included in this study. The associated lesions are frequent, leading to sequelae, all the more important that the head trauma is severe [13]. Lethality is very high in patients with the most serious lesions $[12,14]$. Our populations are mostly deprived as it has been observed in other studies $[6,12]$. Accessibility to care is hindered by its cost. Twenty patients shortened their hospital stay to refer to other traditional practices. This fact, which is also reported in the literature, could be explained by the economic barrier $[6,7,12]$. Upon admission to the emergency department, the management of first aid and imaging is approximately 80,000 FCFA. This is already high for an average monthly income per capita in Burkina Faso which amounts to 26,000 FCFA (\$ 52), making 312,000 FCA (\$ 620) per capita per year. Hospitalization is average 5 days for simple and moderate cases. Fees will be increased in case of extension of hospitalization $[6,12]$. It can be either a surgical procedure or admission to an intensive care unit or the management of an associated trauma $[6,11]$.

Benign forms are generally of good prognosis and the socio-professional reintegration is faster, unlike moderate forms with longer delay $[12,14]$. Patients with severe forms always present rehabilitation problems [4, 11, 13, 14]. Sequelae management is difficult in our conditions of practice. The lack of a rehabilitation and social reintegration center is the main cause. The entourage of the patients cannot fully follow up those who have lost their autonomy. Preventing these injuries is very important. The use of motorcycles should be subject to or conditioned to obtain a driver's license, and the mandatory use of protective helmets. The application of these measures would be an essential asset and could significantly reduce the incidence of these injuries. Promoting and accessible public transit would be a save option for our people.

\section{Conclusion}

Despite advances in resuscitation, overall mortality remains 
heavy. Sequelae are frequent, leading to problems of socio-professional and family reintegration in our developing country. Prevention of these traumas plays an essential role. This would preserve our young and active population whose socio-economic role is no longer to be demonstrated.

\section{Conflict of Interests}

All the authors do not have any possible conflicts of interest.

\section{References}

[1] Agrawal A, Galwankar S, Kapil V, Coronado V, Basavaraju SV, Mc Guire LC and al. Epidemiology and clinical characteristics of traumatic brain injuries in a rural setting in Maharashtra, India. 2007-2009 Int J Crit Illn Inj Sci. 2012; 2 (3): 167-171.

[2] Abdelgadir J, Smith ER, M Punchak, Vissoci JR, C Staton, Muhindo A, and al. Epidemiology and Characteristics of Neurosurgical Conditions at Mbarara Regional Referral Hospital. World Neurosurg. 2017; 102: 526-532.

[3] Smart LR, Mangat HS, Issarow B, McClelland P, Mayaya G, Kanumba E. and al. Severe Traumatic Brain Injury at a Tertiary Referral Center in Tanzania: Epidemiology and Adherence to Brain Trauma Foundation Guidelines. World Neurosurg. 2017; 105: $238-248$

[4] Kamal VK, Agrawal D, Pandey RM. Epidemiology, clinical characteristics and outcomes of traumatic brain injury: Evidences from integrated level 1 trauma center in India. J Neurosci Rural Pract. 2016; 7 (4): 515-525.

[5] Staton CA, Msilanga D, Kiwango G, Vissoci JR, de Andrade L, Lester $\mathrm{R}$, et al. A prospective registry evaluating the epidemiology and clinical care of traumatic brain injury patients presenting to a regional referral hospital in Moshi, Tanzania: challenges and the way forward. Int J Inj Contr Saf Promot. 2017; 24: 69-77.
[6] Hode L, Madougou S, Fatigba HO, Hounnou P, Ebassa K, Hans Moevi AA and al. The Direct Cost of Treatment of Traumatic Brain Injury in a Sub-Saharan African Country (Benin). World Neurosurg. 2017; 99: 210-213.

[7] Dakouré PWH, Diallo M, Traoré ACV, Gandéma S, Barro SD, Traoré IA and al. Trauma related to falls from trees treated in a specialized trauma center in Burkina-Faso-one hundred and six cases treated in one year. Int Orthop. 2015; 39 (12): 2451-6.

[8] Aenderl I, Gashaw T, Siebeck M, Mutschler W. Head injury-a neglected public health problem: a four-month prospective study at Jimma University specialized hospital, Ethiopia. Ethiop J Health Sci. 2014; 24: 27-34.

[9] Chesnut RM, Temkin N, Carney N, Dikmen S, Rondina C, Videtta $\mathrm{W}$, and al. A trial of intracranial-pressure monitoring in traumatic brain injury. N Engl J Med. 2012; 367: 2471-2481.

[10] Eaton J, Hanif AB, Grudziak J, Charles A. Epidemiology, Management, and Functional Outcomes of Traumatic Brain Injury in Sub-Saharan Africa. World Neurosurg. 2017; 108: 650-655.

[11] Taopheeq BR, Babatunde A. Posttraumatic Seizures in a Rural Nigerian Neurosurgical Service. World Neurosurg. 2017; 104: 367-371.

[12] Kaboré AF, Ki BK, Ouédraogo A, Traore SSI, Traore IA, Bougouma CTH and al. Head Computed Tomography Scan in Isolated Traumatic Brain Injury in a Low-Income Country. World Neurosurg. 2017; 107: 382-388.

[13] Capizzi A, Woo J, Verduzco-Gutierrez M. Traumatic Brain Injury: An Overview of Epidemiology, Pathophysiology, and Medical Management. Med Clin North Am. 2020; 104 (2): 213-238.

[14] Desai M, Jain A. Neuroprotection in traumatic brain injury. J Neurosurg sci 2018; 62: 563-73.

[15] Williams E, Martini A, Jackson H, Wagland J, Turner-Stokes L. Time between acquired brain injury and admission to community-based rehabilitation: differences in cognitive and functional gains. Brain Injury. 2020; 34 (6): 713-722. 